\title{
The Analysis on Spatial-Temporal Evolution and Impacting Factors of Residential Land Price in Hangzhou: Evidence Based on Spatial Econometric Model
}

\author{
Haizhen Wen ${ }^{1, a}$ and Luhong Chu ${ }^{1, b *}$ \\ ${ }^{1}$ The Center for Real Estate Study, Zhejiang University, Hangzhou 310027, China \\ awenhaizhen@zju.edu.cn, bchulh2011@163.com \\ *The corresponding author
}

Keywords: Land price; Hedonic price model; Spatial econometric model; Spatial effect; Temporal effect

\begin{abstract}
In the context of rapid urbanization in China, the land market has become one of the focuses of the whole society. Based on the residential land transaction data from May 2006 to March 2010 in Hangzhou, this paper applies the hedonic price model of spatial econometrics to study the evolving trend and the influencing factors of land prices from two aspects of time and space. The results show that, compared with OLS estimation result, the estimated results of spatial econometric model improve significantly. And floor area ratio and land grade have a significant impact on land prices. At the spatial level, there is a significant spatial dependency between the error terms of land prices, and the price fluctuation between the adjacent lands is significant, besides the distance to the urban landscape center West Lake has a significant negative impact on the land price. In temporal dimension, land prices have an obvious rising trend, but the rising degree of land prices declines evidently in the period of international financial crisis.
\end{abstract}

\section{Introduction}

Urban land price is an important means to regulate the supply and demand in land market, and it is also an important index to measure whether the land resources are effectively utilized and allocated rationally. With the rapid development of urbanization and urban economy in China, the urban land price has constantly changed in two dimensions of time and space. The research on the evolution and influencing factors of land prices has been one of the focuses of many scholars, and has made many achievements [1-7]. Due to the spatial fixation of land, land prices tend to have spatial dependence. The traditional regression model assumes that the spatial distribution of land prices is independent of each other and can't measure the spatial effect of land prices, which may lead to the bias of the model estimation coefficients. This paper attempts to construct a spatial econometric model to test whether there is spatial effect of land prices. On this basis, this paper analyzes the temporal-spatial evolution and the microscopic factors of land prices, and makes an empirical analysis of the residential land market in Hangzhou.

\section{Literature Review}

In recent years, many scholars at home and abroad have studied the influence factors of land prices or value. McDonald and McMillen [8] had studied the changes of land value between 1960s and 1980s in Chicago, and analyzed the employment center identification and its impact on housing land value. The results show that the employment center has a positive impact on the land value. Sivitanidou [9] was the first to attempt to explore the changes in LA's multicenter office business land value gradient. The empirical results show that the gradient of office land value became more moderate between 1989 and 1994. The author argues that the recent information revolution is leading to a weakening of the spatial link between office business activities and large business centers, increasingly leading to fragmented spatial patterns.

Attack and Margo [10] examined the price gradient of vacant land in New York City for 66 years 
from 1835 to 1900 . The authors argue that improvements in public transport and the expansion of economic activity can help explain the decline in price gradients. Clapp et al [11] used the residential transaction data from 1975 to 1992 in Fairfax area, to establish a hedonic price equation to estimate changes in the value of residential land. The results show that demographic factors and technological innovations shape the surface of land value.

Other scholars also have been studied the China's land market. Wu et al [5] chosen the micro-data of land transaction in Beijing from 2004 to 2008, and analyzed the influence degree of life convenience, traffic convenience, environment facility convenience and work convenience on the transfer price of residential land. The results show that these four types of exogenous latent variables have significant influence on the residential land prices, but the degree of influence is different.

Based on the microscopic data of residential land in Beijing from 2004 to 2009, Dong et al [6] validated and predicted the influence factors and spatial heterogeneity of residential land prices. It is found that there are significant differences in the intensity of land use intensity between key primary schools, rail transit and parks and other facilities in different regions. Qin et al [7] found that the distance to the CBD, volume ratio and the way of land transfer have a significant impact on land prices.

These studies have analyzed the influence factors of land prices from different aspects, which can summarize to three kinds of variables: locational factors, land factors and market factors. Location factors include the distance to the CBD, the degree of convenience etc., and plots factors include floor area ratio (FAR), land use, transfer mode etc., and market factors include time factors, technical factors etc.. These studies provide a reference for our further research.

\section{Data and Variable}

This article selects the auction data of residential land transaction from May 2006 to March 2010 in Hangzhou, a total of 147 samples. The scope of land transactions covers the main six urban areas of Hangzhou, including Shangcheng District, Xiacheng District, Gongshu District, Jianggan District, Xihu District, Binjiang District.

In the study, the land price is chosen as the dependent variable, and the independent variables are divided into three types: land characteristic variable, location characteristic variable and time trend variable. The meaning of independent variables and their expected effect on the dependent variables are shown in Table 1. 
Table 1 Description and quantification of the variables

\begin{tabular}{|c|c|c|}
\hline Variables & Description and quantification & Expected symbol \\
\hline Land price $(\mathrm{P})$ & $\begin{array}{l}\text { Land price per unit area (land transaction price divided by land } \\
\text { area) }\left[\text { Million } / \mathrm{m}^{2}\right]\end{array}$ & \\
\hline $\operatorname{FAR}\left(\mathrm{X}_{1}\right)$ & Construction area and plot area ratio & + \\
\hline Land grade $\left(\mathrm{X}_{2}\right)$ & $\begin{array}{c}\text { Divided into } 7 \text { levels, assigning } 1 \text { to } 7 \text { from the } 1 \text { th to the } 7 \text { th } \\
\text { grade respectively }\end{array}$ & - \\
\hline Wulin distance $\left(\mathrm{X}_{3}\right)$ & $\begin{array}{l}\text { The recently linear distance from transfer land to the Wulin } \\
\text { Square }[\mathrm{km}]\end{array}$ & - \\
\hline $\begin{array}{l}\text { Qianjiang New Center } \\
\text { distance }\left(\mathrm{X}_{4}\right)\end{array}$ & $\begin{array}{l}\text { The recently linear distance from transfer land to the } \\
\text { Hangzhou Grand Theater in Qianjiang New Center }[\mathrm{km}]\end{array}$ & - \\
\hline West Lake distance $\left(\mathrm{X}_{5}\right)$ & $\begin{array}{l}\text { The recently linear distance from transfer land to the West } \\
\text { Lake }[\mathrm{km}]\end{array}$ & - \\
\hline $\mathrm{T}_{0}$ & $\begin{array}{l}\text { Dummy variable, indicating whether the land was sold in the } \\
\text { first half of } 2006 \text { ( } 1 \text { is "yes", otherwise it is } 0 \text {, the same below) }\end{array}$ & To be determined \\
\hline $\mathrm{T}_{1}$ & $\begin{array}{l}\text { Dummy variable, indicating whether the land was sold in the } \\
\text { second half of } 2006\end{array}$ & To be determined \\
\hline $\mathrm{T}_{2}$ & $\begin{array}{l}\text { Dummy variable, indicating whether the land was sold in the } \\
\text { first half of } 2007\end{array}$ & To be determined \\
\hline $\mathrm{T}_{3}$ & $\begin{array}{l}\text { Dummy variable, indicating whether the land was sold in the } \\
\text { second half of } 2007\end{array}$ & To be determined \\
\hline $\mathrm{T}_{4}$ & $\begin{array}{l}\text { Dummy variable, indicating whether the land was sold in the } \\
\text { first half of } 2008\end{array}$ & To be determined \\
\hline $\mathrm{T}_{5}$ & $\begin{array}{l}\text { Dummy variable, indicating whether the land was sold in the } \\
\text { second half of } 2008\end{array}$ & To be determined \\
\hline $\mathrm{T}_{6}$ & $\begin{array}{c}\text { Dummy variable, indicating whether the land was sold in the } \\
\text { first half of } 2009\end{array}$ & To be determined \\
\hline $\mathrm{T}_{7}$ & $\begin{array}{c}\text { Dummy variable, indicating whether the land was sold in the } \\
\text { second half of } 2009\end{array}$ & To be determined \\
\hline $\mathrm{T}_{8}$ & $\begin{array}{c}\text { Dummy variable, indicating whether the land was sold in the } \\
\text { first half of } 2010\end{array}$ & To be determined \\
\hline
\end{tabular}

\section{Results and Discussion}

Space Effect Test. According to the principle of spatial econometric, it is necessary to test the spatial effect of land prices before using the spatial econometric model. The commonly used method is Moran's I index method. If there is spatial effect, then the spatial econometric model will be constructed to estimate the spatial effect.

In this paper, 147 distribution plots are plotted using ArcView3.3, and the global Moran's I of land price is 0.3853 calculated by OpenGeoda software which is significant at $1 \%$ level. The scatter diagram is shown in Fig. 1. This indicates that the spatial distribution of land prices in Hangzhou has obvious spatial effect, which shows that the spatial distribution of land prices is not stochastic, but has spatial correlation. Therefore, the spatial econometric model can be used for estimation.

Comparing the dependent and independent variables into various forms of the model (natural and unnatural logarithms), it is found that the dependent variable (land price) in natural logarithm form, and the independent variable in logarithmic form into the logarithmic linear model can get the best fitting effect. Therefore, this paper constructs the characteristic price model of logarithmic linear: spatial lag model (SLM) and spatial error model (SEM). The results of two spatial econometric models are obtained using OpenGeoda software using 147 land transaction data, which are shown in Table 2. Of course, Table 2 also shows the results of OLS estimation for comparison.

Since the SLM and SEM are estimated by the maximum likelihood method, the goodness-of-fit $\mathrm{R}^{2}$ based on the sum of residual square-sum decomposition is no longer suitable as an indicator of the pros and cons of the discriminant model, but can be estimated by the log-likelihood function (LogL), Akaike Information Criterion (AIC) and Schwartz's Rule (SC). The results of the test criteria in Table 2 show that both the SLM and SEM results are better than the OLS estimates 
because the LogL values for SLM and SEM are greater and the AIC and SC values are smaller than the OLS results. After comparing the results of SLM and SEM, it is found that SEM has higher LogL value, more significant LR value and smaller AIC value and SC value compared with the results of SLM, which shows that SEM has better estimation effect. This indicates that there exists spatial dependence between regression errors of land prices in Hangzhou.

Table 2 Estimated results of OLS, SLM and SEM

\begin{tabular}{|c|c|c|c|c|c|c|}
\hline \multirow[b]{2}{*}{ Variables } & \multicolumn{2}{|c|}{ OLS } & \multicolumn{2}{|c|}{ SLM } & \multicolumn{2}{|c|}{ SEM } \\
\hline & $\begin{array}{l}\text { Regression } \\
\text { coefficients }\end{array}$ & $\mathrm{P}$ & $\begin{array}{l}\text { Regression } \\
\text { coefficients }\end{array}$ & $\mathrm{P}$ & $\begin{array}{l}\text { Regression } \\
\text { coefficients }\end{array}$ & $\mathrm{P}$ \\
\hline (Constant) & $0.6152 * *$ & 0.0167 & 0.3612 & 0.1149 & $0.5523 * *$ & 0.0264 \\
\hline FAR & $0.3203 * * *$ & 0.0000 & $0.2765^{* * *}$ & 0.0000 & $0.2929 * * *$ & 0.0000 \\
\hline Land grade & $-0.1953 * * *$ & 0.0000 & $-0.1464 * * *$ & 0.0000 & $-0.1536 * * *$ & 0.0000 \\
\hline Wulin distance & -0.0053 & 0.6650 & 0.0045 & 0.6835 & -0.0157 & 0.3985 \\
\hline $\begin{array}{l}\text { Qianjiang New } \\
\text { Center distance }\end{array}$ & 0.0097 & 0.2110 & 0.0032 & 0.6440 & 0.0062 & 0.5913 \\
\hline $\begin{array}{l}\text { West Lake } \\
\text { distance }\end{array}$ & $-0.0367 * * *$ & 0.0030 & $-0.0388 * * *$ & 0.0003 & $-0.0344 *$ & 0.0536 \\
\hline $\mathrm{T}_{1}$ & -0.0884 & 0.4845 & -0.1027 & 0.3561 & -0.0703 & 0.5039 \\
\hline $\mathrm{T}_{2}$ & -0.0780 & 0.5189 & -0.0793 & 0.4559 & -0.0914 & 0.5044 \\
\hline $\mathrm{T}_{3}$ & $0.6078 * * *$ & 0.0000 & $0.5594 * * *$ & 0.0000 & $0.6600 * * *$ & 0.0000 \\
\hline $\mathrm{T}_{4}$ & $0.7581 * * *$ & 0.0000 & $0.7479 * * *$ & 0.0000 & $0.6942 * * *$ & 0.0000 \\
\hline $\mathrm{T}_{5}$ & $0.2436^{*}$ & 0.0862 & $0.2448 * *$ & 0.0488 & $0.2295^{*}$ & 0.0556 \\
\hline $\mathrm{T}_{6}$ & $0.4862 * * *$ & 0.0002 & $0.4417 * * *$ & 0.0001 & $0.4567 * * *$ & 0.0000 \\
\hline $\mathrm{T}_{7}$ & $1.0369 * * *$ & 0.0000 & $0.9722 * * *$ & 0.0000 & $1.0119 * * *$ & 0.0000 \\
\hline $\mathrm{T}_{8}$ & $0.9663 * * *$ & 0.0000 & $0.9492 * * *$ & 0.0000 & $1.0001 * * *$ & 0.0000 \\
\hline$\rho$ & & & $0.2686 * * *$ & 0.0000 & & \\
\hline$\lambda$ & & & & & $0.4712 * * *$ & 0.0000 \\
\hline Statistical test & \multicolumn{2}{|c|}{ Statistical value } & \multicolumn{2}{|c|}{ Statistical value } & \multicolumn{2}{|c|}{ Statistical value } \\
\hline $\mathrm{R}^{2}$ & \multicolumn{2}{|c|}{0.8481} & \multicolumn{2}{|c|}{0.8694} & \multicolumn{2}{|c|}{0.8744} \\
\hline $\log L$ & \multirow{2}{*}{\multicolumn{2}{|c|}{0.3796}} & \multicolumn{2}{|c|}{10.4834} & \multicolumn{2}{|c|}{10.8261} \\
\hline LR & & & \multicolumn{2}{|c|}{$20.2075 * * *$} & \multicolumn{2}{|c|}{$20.8929 * * *$} \\
\hline AIC & \multicolumn{2}{|c|}{27.2407} & \multicolumn{2}{|c|}{9.0332} & \multicolumn{2}{|c|}{6.3479} \\
\hline $\mathrm{SC}$ & \multicolumn{2}{|c|}{69.1068} & \multicolumn{2}{|c|}{53.8897} & \multicolumn{2}{|c|}{48.2139} \\
\hline
\end{tabular}

$* * *, * *, *$ respectively by $1 \%, 5 \%, 10 \%$ level of significance test.

From the above analysis results, SEM is the best estimate, so the follow-up analysis will use the estimation results of SEM.

Analysis of Parcel Characteristic Features. According to the regression results of SEM in Table 2, the estimated coefficients of FAR and land grade are 0.2929 and -0.1536 respectively, which are all significant at $1 \%$ level. Among them, the FAR has the greatest impact on the land price. Under the same conditions, the FAR increased by 1 unit, the land price will increase by about $34.03 \%\left(\mathrm{e}^{0.2929}-1\right.$, the same below), indicating that developers are very valued on the FAR, and tend to obtain high FAR of land. Similarly, for every 1 increase in land grade, land price will fall by about $14.24 \%$, indicating that the land grade has a considerable impact on land prices. The above analysis shows that the FAR and land grade have a significant impact on land prices, which can be used as an important lever to adjust the land price.

Spatial Analysis of Land Prices. According to the regression results of SEM, the spatial correlation coefficient $\lambda=0.4712$, the value is large and significant at $1 \%$ level, indicating that the land price has a strong spatial dependence of error, and the price fluctuation between adjacent land blocks has a great correlation in Hangzhou. At the same time, the estimated coefficients of Wulin 
distance, Qianjiang New Center distance and West Lake distance are -0.0157, 0.0062, -0.0344 respectively. However, the estimated coefficients of the three regional variables are very small, and only the coefficient of West Lake distance is significantly negative, the other two are not significant and the sign of Qianjiang New Center distance is contrary to expectation. This may be due to the fact that the correlation coefficient between the three variables is high and there is a high collinearity.

As the Wulin Square and Qianjiang New Center are not significant influenced on land prices, so we only analyze the effect of West Lake distance on land prices. The coefficient of West Lake distance is -0.0344 and is significant at the $10 \%$ level, indicating that the land price decreases by approximately $3.38 \%$ for every $1 \mathrm{~km}$ increase in distance to the West Lake when the other conditions are maintained. The relationship between land prices and the West Lake distance is $\mathrm{P}=\exp \left(-0.0344 \mathrm{X}_{5}\right)$, specifically shown in Fig. 2 in the solid line. The results are in line with expectations, indicating that the West Lake has a greater impact on land prices as the landscape center.

In order to facilitate comparison, the relationship between two curves of the land price and the West Lake distance are plotted in Fig. 2. The solid line shows the direct impact of West Lake distance on land prices, while the dotted line shows the function relationship between the land price and the West Lake distance after the other independent variables are entered into the SEM. Fig. 2 and the corresponding formula shows that, without considering the impact of other factors, the impact of the West Lake distance on land prices is relatively weak, only about $4 \%$ of all the influencing factors.

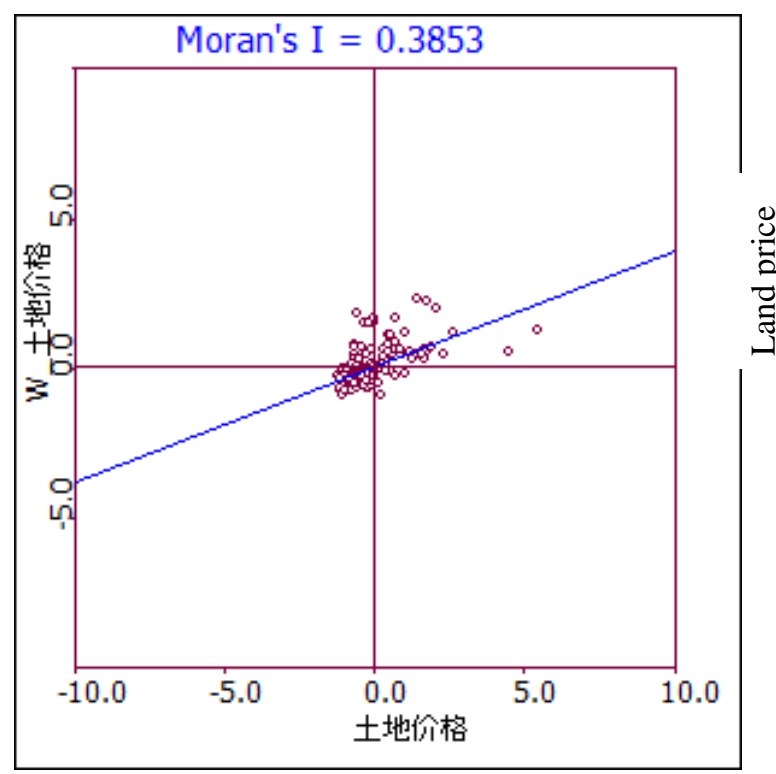

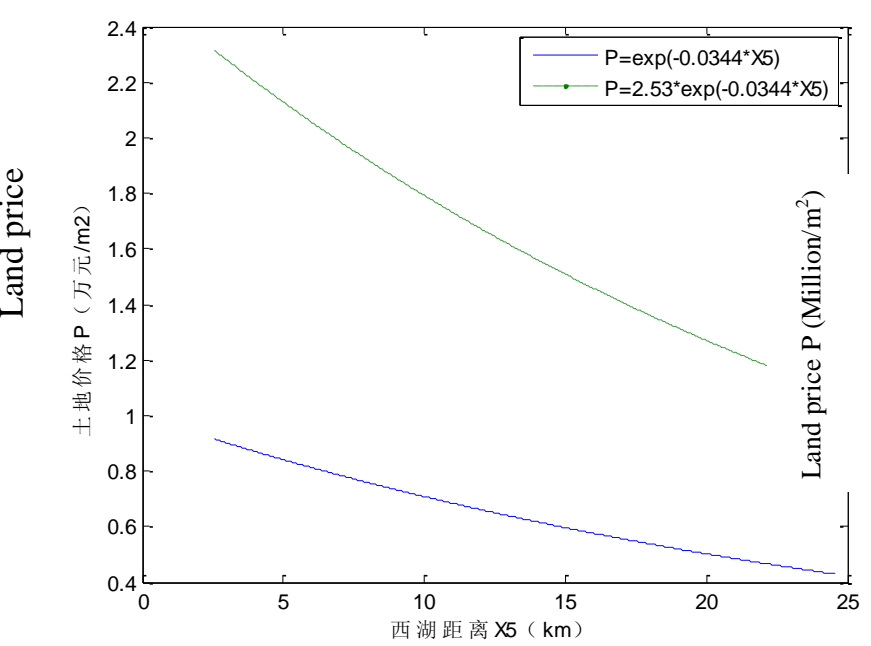

Figure 2. Function, Land price rice and West Lake distance

Figure 1. Moran's I scatter plot of land price in Hangzhou

Time Trend Analysis of Land Price. The estimated coefficients of $\mathrm{T}_{1} \sim \mathrm{T}_{8}$ are $-0.0703,-0.0914$, $0.6600,0.6942,0.2295,0.4567,1.0119,1.0001$, and the estimated coefficients of $\mathrm{T}_{1}$ and $\mathrm{T}_{2}$ are not significant, $\mathrm{T}_{5}$ is significant at the level of $10 \%$, and the others are significant at the level of $1 \%$. The empirical results show that relative to the first half of $2006\left(\mathrm{~T}_{0}\right.$ is the base period), the land price in each half year increased except for the second half of 2006 and the first half of 2007, indicating that the overall trend of land prices is continued to rise (see Fig. 3). The estimated coefficients of $T_{1}$ and $T_{2}$ are not significant, indicating that the land price in the second half of 2006 and the first half of 2007 are not statistically different from those in the first half of 2006. While the coefficients of $\mathrm{T}_{3}$ and $\mathrm{T}_{4}$ are little different, indicating that in the second half of 2007 and the first half of 2008, land prices rose roughly the same, about $90 \%$ to $100 \%$. Compared with $\mathrm{T}_{3}$ and $\mathrm{T}_{4}$, the coefficients of $T_{5}, T_{6}$ are significantly smaller, especially the coefficient of $T_{5}$ is only 0.2295 , only 
about one-third of $\mathrm{T}_{5}$, indicating that compared with the first half of 2006, the second half of 2008 and the first half of 2009 , the land price despite the rise, but the decline was down, about $25 \%$ to $58 \%$. This is because in September 2008 the international financial crisis broke out, greatly affected the real estate market is expected to rise, resulting in many land auction, so land prices rose little. The coefficients of $\mathrm{T}_{7}$ and $\mathrm{T}_{8}$ are also little difference, but the value increased significantly, more than 1, indicating that in the second half of 2009 and the first half of 2010, the land price rose sharply, or more than $170 \%$. This is mainly because in November 2008, the state in response to the financial crisis to relax the regulation of the real estate market, the effect began to appear in the second half of 2009, resulting in the boom of real estate market boom, land prices naturally high.

The trend of the real land price over time and the land price trend obtained by regression are plotted in Fig. 3. Among them, the statistical time trend of land prices is based on the estimated time coefficient of regression according to the half year as a time period, assuming the land price in the first half of 2006 is 1, Y2006 H1 represented the first half of 2006, and Y2006 2 represented the second half of 2006, analogy. Nominal land-time trends are based on trends in the mean value of real land price over time. As can be seen from Fig. 3, the return of land price and the actual situation is basically consistent.

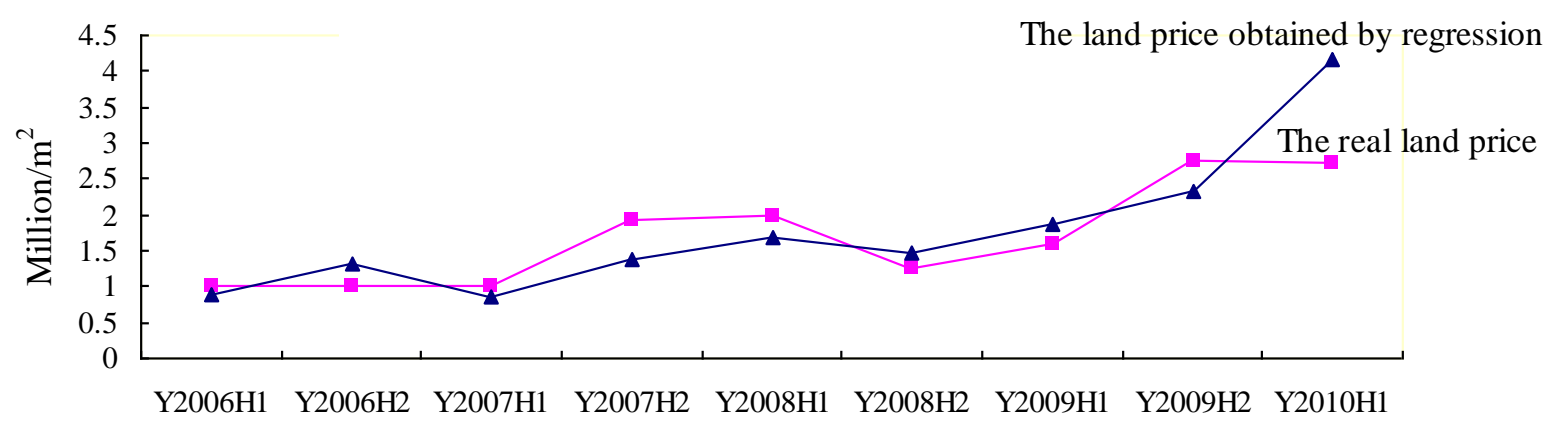

Figure 3. Trend of land price in time dimension

\section{Conclusion}

This paper takes use of the spatial econometric model to empirically analyze the temporal and spatial evolution of land prices and its influencing factors in Hangzhou. It is found that the results of spatial econometric model are obviously better than those of OLS estimation; the land price has a significant spatial effect, and mainly shows the spatial dependence of the error term, so the fitting result of spatial error model (SEM) is better.

The empirical results of spatial error model show that the effect of floor area ratio (FAR) and land grade on land prices is significant. At the spatial level, there is a significant spatial dependency between the error terms of the land price regression model, indicating that there is a strong correlation between the price fluctuation of the adjacent land; and the distance to the urban landscape center West Lake has a significant negative impact on the land price. On the time dimension, there is a clear upward trend in the price of land, but during the financial crisis, the land price declined significantly as a result of the financial crisis.

\section{References}

[1] Y. Wang, W. Tang and S.H. Jia: The Journal of Real Estate Finance and Economics, Vol. 53 (2016) No.2, p.218-245.

[2] H. Cai, J.V. Henderson and Q. Zhang: Rand Journal of Economics, Vol. 44 (2013) No.3, p.488-521. 
[3] W.J. Shen, C.C. Feng and Y.S. Hou: Research of Urban Development, Vol. 21 (2014) No.3, p.4-8. (In Chinese)

[4] H. Jiang: The Land Area, The Degree of Competition and its Impact on Land Unit Price (MS., Zhejiang University, China 2014), p.28 (In Chinese)

[5] W.J. Wu, Z.L. Liu and W.Z. Zhang: Journal of Geographical Sciences, Vol. 65 (2010) No.6, p.676-684. (In Chinese)

[6] G.P. Dong, W.Z. Zhang and W.J. Wu: Journal of Geographical Sciences, Vol. 66 (2011) No.6, p.750-760. (In Chinese)

[7] B. Qin and L. Sun: Chinese Journal of Soil Science, Vol. 24 (2010) No.3, p.70-74. (In Chinese)

[8] J. F. McDonald and D. P. McMillen: Environment and Planning, Vol. 22 (1990), p.1561-1574.

[9] R. Sivitanidou: Journal of Urban Economics, Vol. 42 (1997) No.1, p.79-97.

[10] J. Atack and R. A. Margo: Journal of Real Estate Finance and Economics, Vol. 16 (1998) No.2, p.151-172.

[11] J. M. Clapp, M. Rodriguez and R. K. Pace: Journal of Real Estate Finance and Economics, Vol. 22 (2001) No.1, p. 43-61. 